\title{
Histological Aspects of a Hypersensitive Response in Poplar to Melampsora larici-populina
}

\author{
F. Laurans and G. Pilate
}

Institut National de la Recherche Agronomique (INRA), Station d'Amélioration des Arbres Forestiers, F 45160 ARDON, France. Accepted for publication 22 December 1998.

\section{ABSTRACT}

Laurans, F., and Pilate, G. 1999. Histological aspects of a hypersensitive response in poplar to Melampsora larici-populina. Phytopathology 89: 233-238.

The course of the infection and development of the biotrophic fungus Melampsora larici-populina on leaf tissue from the hybrid poplar Populus deltoides $\times$ P. nigra 'Ogy' was monitored at the histological level. Leaf disks were inoculated with one of two rust physiological races (E1 and E2), resulting in interactions that were either incompatible (race E1) or compatible (race E2). In the compatible interaction, the fungus rapidly colonized the leaf without inducing any apparent host response. Symptoms appeared on the leaf several days after inoculation just prior to spore dissemination. The incompatible interaction was characterized by the early collapse and disorganization of cytoplasm of infected cells $17 \mathrm{~h}$ after inoculation and within $2 \mathrm{~h}$ after the appearance of the first haustoria. Resistance to M. larici-populina was mediated through a hypersensitive response, since it was extremely localized and involved only the few cells that were in the immediate vicinity of each infected cell.
Interspecific hybrids of Populus spp. are subject to leaf rust caused by Melampsora species. The most widespread and frequently occurring of these in Europe is M. larici-populina Kleb. (19). Rust infection causes premature defoliation and can severely reduce growth. Repeated infections over successive years can result in the complete loss of the plantation. In order to limit the damage resulting from rust attacks, poplar breeders are attempting to select resistant clones $(10,15,26)$. Different physiological races of Melampsora species exist that exhibit pathogenic variation (17). As a result, host resistance can be overcome by this pathogen, as has occurred recently with the appearance of race E3 in 1987 and more recently of race E4 (18). Pathologists have isolated several of these physiological races, which can be distinguished by in vitro assays by their differential behavior toward different poplar clones (19). Very little information exists regarding the physiological aspects of poplar- $M$. larici-populina interactions. Histological studies are similarly very scarce, and those that have been conducted have focused mainly on interactions observed on infected poplar leaves collected in the field (e.g., 25). In this paper, we describe, at the histological level, the events that occur after the inoculation of a poplar hybrid cultivar under controlled conditions with one of two physiological races of $M$. laricipopulina, E1 and E2. The poplar hybrid cultivar used is resistant to E1 and susceptible to E2.

\section{MATERIALS AND METHODS}

The study was conducted on the hybrid poplar cultivar Ogy $(P$. deltoides Marsh. $\times$ P. nigra L.). Cuttings were grown in a greenhouse, and leaves were collected from 4-month-old plants. Cultivar Ogy is resistant to physiological races E1 and E3 of M. laricipopulina and susceptible to races E2 and E4.

Urediniospores from physiological races E1 and E2 of M. larici-populina were multiplied in a growth chamber under controlled conditions on leaves of differential $P$. deltoides $\times P$. nigra clones (cultivar Robusta for M. larici-populina race E1 and cultivar Ogy for

Corresponding author: G. Pilate; E-mail address: pilate@orleans.inra.fr

Publication no. P-1999-0118-01R

(c) 1999 The American Phytopathological Society
M. larici-populina race E2) with a 16 -h photoperiod at $20^{\circ} \mathrm{C}$ and fluorescent light $\left(25 \mu \mathrm{mol}^{-2} \cdot \mathrm{s}^{-1}\right)$, as previously described (19).

Foliar disks (25 $\mathrm{mm}$ in diameter) were excised from mature leaves of greenhouse-grown plants at the leaf position defined as leaf plastochron index 5 to 8 (LPI 5 to 8 ). The LPI is counted basipetally from the index leaf (lamina approximately $20 \mathrm{~mm}$ in length) at the shoot apex (9). These leaf disks were inoculated with either physiological race E1 or E2. Urediniospores were applied to the lower (abaxial) surfaces of the foliar disks with a paint brush. After inoculation, the disks were sprayed with distilled water and floated on distilled water with the lower leaf surfaces up. Control foliar disks were sprayed only with distilled water. All of the foliar disks used for a given time originated from the same leaf. Environmental conditions after inoculation were as described for spore multiplication. In order to verify the purity of the E1 and E2 inocula, leaves from differential clones were also inoculated, and some leaf disks were kept for 15 days until the uredia were completely developed. In order to estimate the germination rate, an aliquot of each inoculum was dispersed in water and then sprayed onto solidified agar ( $15 \mathrm{~g} /$ liter). The germination percentage was scored $24 \mathrm{~h}$ later.

Scanning electron microscopy. Foliar disks for scanning electron microscopy (SEM) were collected $2 \mathrm{~h}, 6 \mathrm{~h}$, and 7 days after inoculation. Foliar disks were attached to supports with silver paint, coated with gold-palladium in a sputter coater, and observed under a scanning electron microscope (Stereoscan 90, Cambridge Scientific Instruments, Cambridge, England).

Light microscopy. For surface observations, foliar disks were collected $6 \mathrm{~h}$ after inoculation, cut into fragments of about $1 \mathrm{~cm}^{2}$, and immersed in a clearing-staining solution containing ethanol, $50 \%$ (vol/vol), chloroform, 25\% (vol/vol), lactic acid, $21 \%$ (vol/ vol), chloral hydrate, $7.5 \%(\mathrm{wt} / \mathrm{vol})$, and aniline blue, $0.01 \%(\mathrm{wt} / \mathrm{vol})$ for $48 \mathrm{~h}$ at room temperature. The leaf fragments were then removed, placed for $24 \mathrm{~h}$ in a concentrated chloral hydrate solution $(2.5 \mathrm{~g} / \mathrm{ml}$ of water), and finally rinsed rapidly in distilled water (1). The cleared specimens were mounted on slides and viewed under a light microscope (Laborlux 12, Leitz, Rueil-Malmaison, France).

For observations of sections, foliar disks were collected at 1-h intervals up to $25 \mathrm{~h}$ after inoculation and then at 48, 51, 72, 96, 116, $117,120,121,122,124,140,144,147$, and $168 \mathrm{~h}$ after inoculation.

Fragments $\left(5 \mathrm{~mm}^{2}\right)$ were cut from leaf disks, infiltrated under a slight vacuum in $2.5 \%$ glutaraldehyde solution in $0.1 \mathrm{M}$ phosphate 
buffer ( $\mathrm{pH} 7.5$ ), and fixed overnight at $4{ }^{\circ} \mathrm{C}$ with slow agitation. Fixed samples were rinsed in $0.1 \mathrm{M}$ phosphate containing $3 \%$ glucose and dehydrated in a graded ethanol series. Leaf segments were then embedded in glycolmethacrylate resin (Technovit 7100, Kulzer, Wehrheim, Germany) according to the manufacturer's instructions.

Semithin sections $(1 \mu \mathrm{m})$ were cut with a tungsten carbide knife on a microtome (Wetzlab 1400, Leitz). Sections were stained with $1 \%(\mathrm{wt} / \mathrm{vol})$ toluidine blue $\mathrm{O}$ aqueous solution, mounted on glass slides with Canada balsam, and examined under a Laborlux 12 light microscope.

The number of cells in a field of view was calculated by averaging of the number of cells present in 100 different fields. The number of haustorium-containing cells and the number of collapsed cells were determined by counting 200 to 400 microscope fields per time point of the time course. The degree of stomatal penetration was assessed on 10 different slides with an average of five transverse sections per slide. To compare the compatible and incompatible systems, a two-sample $t$ test was used in statistical analyses.

\section{RESULTS}

Macroscopic observations of disease symptoms. The development of rust in infected leaves was monitored at the macroscopic level over a period of 10 days after inoculation with either physiological race E1 or E2. In the compatible interaction (E2/ Ogy), chlorotic flecks were observed on the lower epidermis of infected leaves 5 days after inoculation. These flecks were localized at the sites where the uredinia would later emerge. By 7 days after inoculation, the uredinia had erupted from the leaf epidermis and were readily seen as orange pustules. When mature, these uredinia reached a diameter of 1 to $2 \mathrm{~mm}$. During the following days, urediniospores were released and disseminated. Uredinia were uniformly distributed on the foliar surface and covered the whole leaf blade but did not develop on leaf veins. The number of uredinia per leaf disk ranged from 70 to 105 .

In the incompatible interaction (E1/Ogy), infected leaves did not show any apparent disease symptom, even 10 days after inoculation. No necrosis was visible to the naked eye, and at the macroscopic level, these leaves were similar in appearance to uninfected control leaves. Microscopic observations performed throughout the time course on control leaf disks inoculated with water did not reveal the presence of any necrosis or damage at the cellular level.

Germination and formation of infection structures. The germination rates of freshly multiplied spores were similar for E1 and E2 and ranged from 85 to $95 \%$. Most of the urediniospores from both races germinated very well on poplar leaf surfaces.

The main preinfection events (i.e., germination, attachment to the host leaf surface, and differentiation of infection structures) were observed by SEM and light microscopy. During these early stages of the infection, we were unable to detect any differences between compatible and incompatible interactions.

Urediniospores started to germinate within 45 min after inoculation and produced branching germ tubes with diameters of less than $3 \mu \mathrm{m}$ on the leaf surface (Fig. 1A and B). The germ tubes did not seem to originate from single germ pores. Occasionally, two or three germ tubes developed from the same urediniospore (Fig. 1B). Adhesion pads (Fig. 1C) of branching germ tubes were clearly visible and were probably involved in the attachment of the fungus to the host surface.

SEM (Fig. 1) allowed us to monitor the formation and development of appressoria (5 to $6 \mu \mathrm{m}$ long), which always occurred over or near a stomatal pore. Generally, each appressorium seemed to be bound to a guard cell (Fig. 2A). Aniline blue staining revealed an appressorium that had differentiated either directly over a stomatal pore or at a short distance from it (Fig. 2A). From each appressorium, an infection peg developed (Fig. 1F) and penetrated the stoma to colonize the plant tissue (Fig. 2B).

Stomatal penetration by germ tubes was achieved $2 \mathrm{~h}$ after inoculation (Fig. 1D). Generally, a single germ tube penetrated each stomatal pore. However, if a stomatal pore was sufficiently large, several germ tubes, possibly produced from different spores, would eventually use the same stoma to penetrate the leaf (Fig. 1E). The presence of several germ tubes within a single stoma probably resulted from the high number of spores inoculated onto the leaf during these experiments. Infection structures could still be observed $6 \mathrm{~h}$ after inoculation and remained on the foliar surface long after penetration of the leaf by the rust fungus.

Host penetration. In order to characterize inter- and intracellular rust penetration, semithin transverse and paradermal sections were observed by light microscopy (Fig. 2B to I). Because of the high spore concentration, $42 \%$ (132 of 316 scored) and 39\% (112 of 285 scored) of the stomata were penetrated by germ tubes from races E2 and E1, respectively. Thus, there were no significant differences between compatible and incompatible interactions with respect to stomatal penetration (Table 1). Two hours after inoculation, the fungus had penetrated the stomata and produced substomatal vesicles (Fig. 2B). These vesicles were about $25 \mu \mathrm{m}$ long with multilobed and thin-walled structures. They had dense cytoplasm and generally two fungal nuclei (not shown). The vesicles became increasingly vacuolated, and their walls became slightly thickened. Nine hours after inoculation, irregular globules (possibly fungal glycogen), which stained pink with toluidine blue, were observed within the vesicles (Fig. 2B). One to three infection hyphae (with diameters of less than $1 \mu \mathrm{m}$ ) differentiated from the substomatal vesicle and branched into the intercellular spaces of the spongy mesophyll (Fig. 2B). The palisade mesophyll was rarely colonized, probably because of its structural arrangement characterized by tightly bound cells with few intercellular spaces. The growing hyphae had dense cytoplasm with small vacuoles. However, by 5 days after inoculation, larger vacuoles had formed, and as in substomatal vesicles, globules that stained pink with toluidine blue (possibly glycogen) were observed. During the early stages of infection, the time course of stomatal penetration and spatial development of intercellular hyphae were identical for races E1 and E2.

Intracellular penetration and colonization of host cells. As early as $17 \mathrm{~h}$ after inoculation in both interactions, the hyphae penetrated host cells and differentiated into haustoria. First, a terminal intercellular mycelial cell came into contact with the wall of a host cell (Fig. 2D). Then the fungal terminal cell differentiated to form a haustorial mother cell (Fig. 2C) with a thickened wall in the contact area (Fig. 2D). A haustorial neck extended from the haustorial mother cell and developed into the lumen of the host cell, and its distal end expanded to form the haustorial body. The haustorial body, which was heavily stained by toluidine blue $\mathrm{O}$, was generally reniform ( 5 to $7 \mu \mathrm{m}$ in diameter) and was commonly observed in juxtaposition to the host nucleus (Fig. 2C). Haustorial formation was observed for both interactions during the whole infection process.

In the compatible interaction (E2/OGY), infected host cells, each containing a haustorium, appeared to be morphologically similar to adjacent noninfected cells (Fig. 2C). At the magnification used for these observations, there was no evidence of physical damage at the site of penetration of host cells nor in the vicinity of the haustorial body. Cell organelles including the nucleus, vacuole, and plastids did not seem to be significantly modified. In addition, there was no evidence of thickening of the host cell wall. The first haustoria were observed $17 \mathrm{~h}$ after inoculation, and their number increased during the following days. Nevertheless, the percentage of leaf cells containing haustoria remained low. Two days after inoculation, only $1.4 \%$ (493 of 35,200 ) of the parenchyma cells contained haustoria. This percentage increased to $7 \%$ during the next 2 days and remained fairly stable $(1,204$ of 17,600 at 4 days and 1,374 of 17,600 at 6 days) during the last stages of fungal development (Table 1). Once the intracellular colonization was well advanced, we observed multiplication and ramification of the intercellular hyphae, which entirely colonized the spaces between parenchyma cells before urediniospore formation was initiated under the lower leaf epidermis. 
As in the compatible interaction, differentiation of the first haustoria was first observed approximately $17 \mathrm{~h}$ after inoculation in the incompatible interaction (E1/OGY). However, necrotic areas with collapsed cells showing disrupted contents developed very rapidly around all the infected cells (Fig. 2E). These areas of necrosis remained extremely localized and involved only a few paren- chyma cells (Fig. 2F). Infected cells then became granular in appearance, their nuclei and plastids became disorganized, and their cytoplasm underwent collapse (Figs. 2E to G). However, cell integrity seemed to be preserved. Cell walls in the incompatible reaction (Fig. 2E and F) appeared more densely stained with toluidine blue than those in the compatible reaction (Fig. 2C), suggesting cell
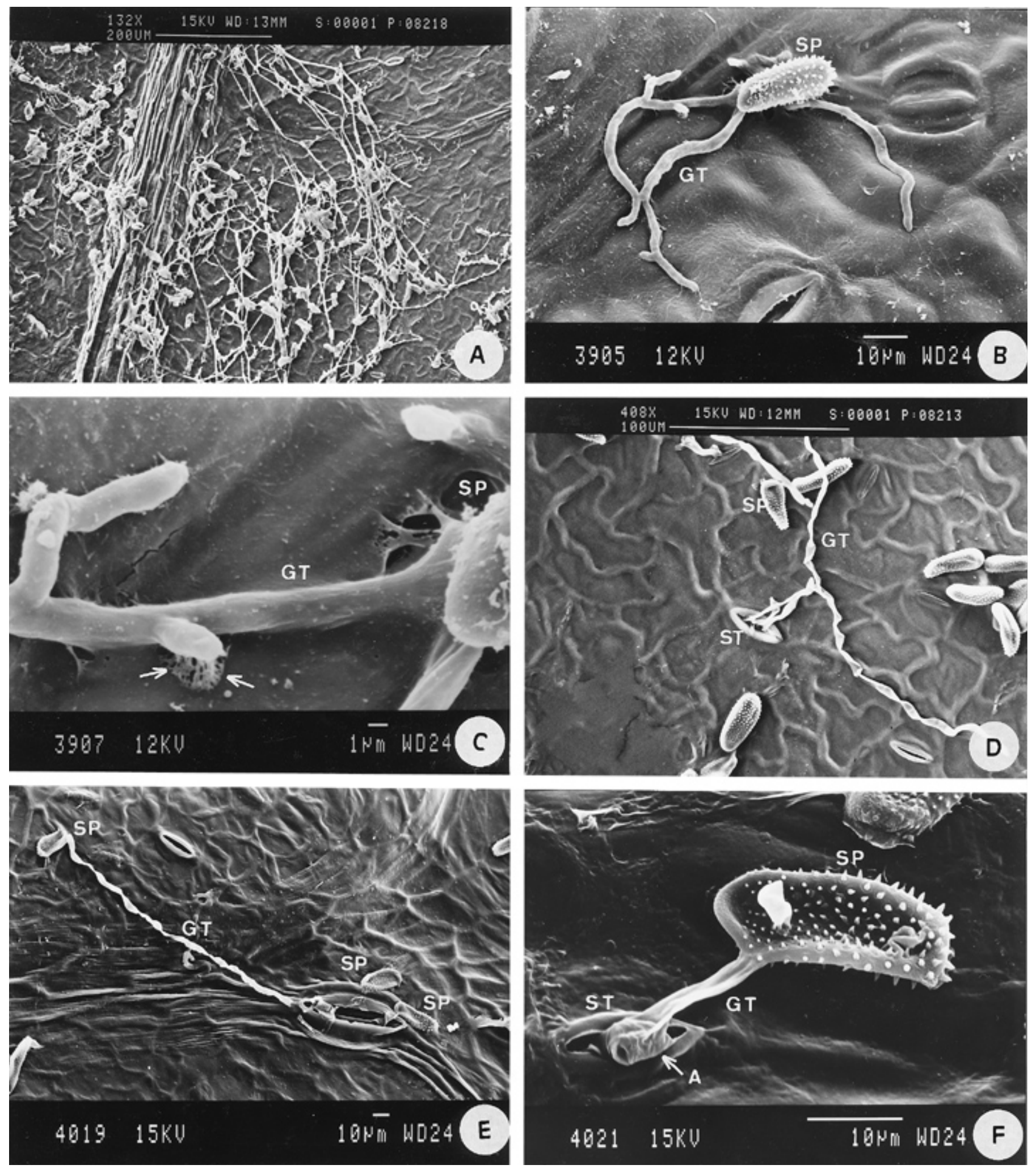

Fig. 1. Germination of urediniospores and formation of infection structures by Melampsora larici-populina races E1 and E2 inoculated on hybrid poplar cultivar Ogy. A, Differentiation of germ tubes from urediniospores on the foliar disk surface $6 \mathrm{~h}$ after inoculation (race E2); B, urediniospore producing branching germ tube on the leaf surface $2 \mathrm{~h}$ after inoculation (race E2); C, adhesion pads (arrows) associated with the branching germ tube (race E1); D, penetration of stoma by germ tubes $2 \mathrm{~h}$ after inoculation (race E2); $\mathbf{E}$, three germ tubes produced from three different urediniospores penetrating one stoma (race E2); and F, development of an appressorium over the stomatal pore (race E1). SP = spore; GT = germ tube; ST = stoma; and A = appressorium. 

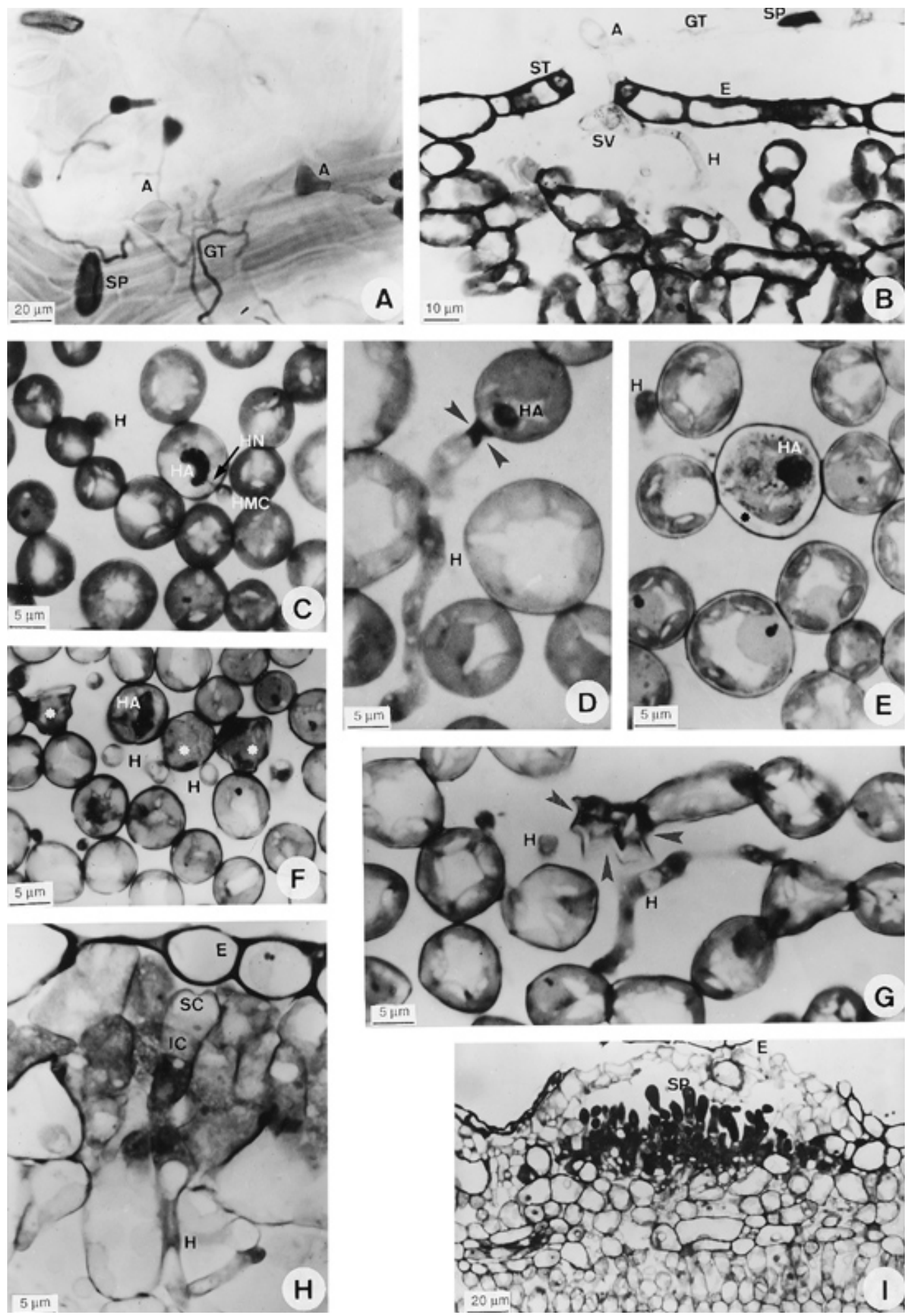

Fig. 2. Development of infection structures and host reaction to colonization by Melampsora larici-populina races E1 and E2 inoculated on hybrid poplar cultivar Ogy. A, Surface view of inoculated leaf $6 \mathrm{~h}$ after inoculation with race E2; an appressorium (A) is formed before penetration. B, Transverse section through infected leaf $9 \mathrm{~h}$ after inoculation with race E1. After penetration, the germ tube develops in the stomatal chamber, and subsequently ramified intercellular hyphae differentiate. C, Paradermal leaf section with intracellular haustorium (HA) developing from haustorial mother cell (HMC) $17 \mathrm{~h}$ after inoculation with race E2. D, Paradermal leaf section with the initial step in haustorium formation: contact of a haustorial mother cell with the wall of a host cell $17 \mathrm{~h}$ after inoculation with race E2. E, Collapse of the host cell (star) after haustorial formation has hindered the establishment of the pathogen 2 days after inoculation with race E1 (note the host cell wall thickening). F, Spongy mesophyll cells shrunken and collapsed (stars) in response to fungal penetration 2 days after inoculation with race E1. The host cell wall appears thickened. G, Plasmolysis of a spongy mesophyll cell (arrows) in contact with intercellular hyphae (H) 2 days after inoculation with race E1. H, Primordium of the uredinia. Initials have divided twice to form three cells, a proximal peridial cell, a central intercalary cell (IC), and a distal sporogenous cell (SC), 4 days after inoculation with race E2. I, Vertical section through erupting subepidermal uredinia revealing urediniospores (SP) 7 days after inoculation with race E2. $\mathrm{A}=$ appressorium; $\mathrm{E}=$ epidermis; $\mathrm{GT}=$ germ tube; $\mathrm{H}=$ intercellular hyphae; $\mathrm{HA}=$ haustorium; $\mathrm{HMC}$ = haustorial mother cell; $\mathrm{HN}=$ haustorial neck; $\mathrm{IC}=$ intercalary cell; $\mathrm{SC}=$ sporogenous cell; $\mathrm{SP}=$ spore; $\mathrm{ST}=$ stoma; and $\mathrm{SV}=$ substomatal vesicle . 
wall thickening. Collapsed haustoria were consistently observed within collapsed cells (Fig. 2E and F). Careful observation of serial sections seemed to indicate that noninvaded cells adjacent to haustorium-containing cells also collapsed. Only a few intact haustoria were observed, and they were always in cells undergoing collapse, probably reflecting the rapidity of the host cell reaction to the attack by the rust fungus.

The number of collapsed cells increased during the 6 days following their first appearance at $19 \mathrm{~h}$ after inoculation. Two days after inoculation, only $0.20 \%$ of the mesophyll cells $(116$ of 57,600$)$ contained haustoria, whereas $0.73 \%$ (426 of 57,600) had collapsed. After 4 days, the number of haustoria-containing cells increased to $0.60 \%$ (337 of 57,600$)$, while $2.36 \%(1,363$ of 57,600$)$ of the host cells had reacted to fungal penetration and exhibited collapse. After 6 days, the number of haustoria-containing cells remained fairly stable at $0.68 \%$ (393 of 57,600), whereas the number of collapsed cells, $3.83 \%$ (2,204 of 57,600), was still increasing. The statistical analysis demonstrated very significant differences between the numbers of haustoria-containing cells in compatible and incompatible interactions 2, 4, and 6 days after inoculation (Table 1). The collapsed cells were observed only in the incompatible interaction. We can assume that the number of collapsed cells recorded includes both haustoria-containing cells (but with the haustoria out of the section plane) and noninvaded cells in the vicinity of a haustoriumcontaining cell. The observed localized necrosis did not seem to affect the viability of the whole leaf. Although intercellular hyphae, possibly originating from late stomatal penetration, still developed late in the course of the incompatible interaction (but to a lesser extent than in the compatible interaction), we never observed the development of uredinia.

Ontogeny of the uredinia. In the compatible interaction, uredinia erupted on the lower sides of the leaves and released urediniospores about 7 days after inoculation (Fig. 2I). The first indication of uredinial formation was a subepidermal aggregation of intercellular hyphae (not shown). Hyphae extended laterally under the epidermis to form a palisade of uredinial initial cells. These initials went through two divisions, leading to the production of three cells: a proximal peridial cell, a central intercalary cell, and a distal sporogenous cell (Fig. 2H). The sporogenous cell, usually swollen at one end, produced spore buds that elongated and divided transversely to form pedicels and immature spore cells (Fig. 2I). As urediniospores matured, the cell wall thickened, ornamentation (i.e., echinulation) developed, and the pedicels shriveled and became separated from the urediniospores. The first urediniospores arose from the center of the uredinium. Successive generations of urediniospores arose within the same uredinium from spore buds produced sympodially from the original sporogenous cell. Elongated, often capitate, paraphyses formed throughout the uredinium and served to rupture the peridium and epidermis that covered the immature uredinium. These paraphyses arose from cells lying at the base of the sorus. Seven days after inoculation, infected host cells showed symptoms of senescence and cytoplasmic organelles appeared disorganized. At this point, the foliar mesophyll was totally colonized by the fungus (Fig. 2I). Sporulation involved the disruption of the epidermis and part of the spongy mesophyll parenchyma (Fig. 2I), which led to decay of the leaf.

\section{DISCUSSION}

Few histological studies have been published describing the pathogenesis of Melampsora species in poplar. Rijkenberg (21) described the structure of urediniospores, germ tubes, and haustoria of M. larici-populina infecting $P$. nigra but did not describe the host reactions. Spiers and Hopcroft (24) briefly described the pathogenesis of $M$. larici-populina and $M$. medusae in susceptible poplar hosts but again concentrated on uredinial development. Later, the same authors reported the pathogenesis of M. larici-populina and M. medusae on poplar grown in the field. For each rust species, they observed a variety of reactions probably resulting from a mixture of races in the natural inoculum (25). Shain and Järlfors (22) characterized histologically the infection processes leading to either compatibility or incompatibility in the M. medusae$P$. deltoides interaction using leaf disks from four different clones that were resistant or susceptible to one isolate of $M$. medusae. These authors did not rule out the possibility that this isolate was in fact a mixture of different races.

In the present study, we describe the events occurring at the histological level after inoculations under controlled conditions of a single poplar clone with two different races of $M$. larici-populina, leading to either a compatible or an incompatible interaction. This study was done in vitro, and it is similar to the system studied by Shain and Järlfors (22). Such a system allows the precise control of experimental conditions, particularly the purity and the density of the rust inoculum (5). In this work, density could not be quantified because concentrated inoculum was needed in order to increase our chances of observing disease symptoms at the histological level. Even under these conditions, less than $10 \%$ of the plant cells contained haustoria. The use of an in vitro system allows for control of physical conditions such as temperature, which is one of the most important variables affecting the pathogenesis of Melampsora rust $(3,20)$. A good correlation between laboratory and field tests (16) also supports the use of this in vitro model. Although we cannot completely rule out potential histological artifacts, we are confident that what was observed at the histological level in this in vitro study is indicative of what happens under natural conditions. Moreover, the use of such a model system allows precise time course studies to be performed after inoculations with either of the two rust races on leaf disks taken from the same leaves. Thus, we can infer that the differences in the host defense reactions observed between the two interactions originated mainly from some differential receptivity of the host toward signals coming from the compatible or incompatible races.

The early phases of infection (i.e., urediniospore germination, appressorium differentiation, stomatal penetration, formation and development of substomatal vesicles, and intercellular hyphal colonization) appeared to be very similar for both races and also similar to M. medusae-P. deltoides interactions (22) and M. liniLinum usitatissimum interactions (13). In fact, the features that we describe here are typical of what is generally observed in rust infections $(8,14)$. The host-specific resistance of the cultivar Ogy toward M. larici-populina is not revealed during these early stages of the infection. Such an observation is perhaps not surprising, since for obligate biotrophic parasites such as rusts, it is generally thought that any defense responses expressed before the

TABLE 1. Frequency of stomatal penetration, haustorial formation, and cell collapse for hybrid poplar cultivar Ogy in compatible and incompatible interactions with the rust fungus Melampsora larici-populina ${ }^{\mathrm{a}}$

\begin{tabular}{|c|c|c|c|c|c|}
\hline \multirow[b]{2}{*}{ Response variable ${ }^{b}$} & \multicolumn{2}{|c|}{ Interaction } & \multicolumn{3}{|c|}{ Student's $t$ test $^{\mathrm{c}}$} \\
\hline & Incomp. & Comp. & $t$ & df & $P$ \\
\hline Stomata per section & 5.70 & 6.28 & 1.52 & 98 & 0.065 \\
\hline Stomata penetrated & 2.24 & 2.66 & 1.69 & 98 & 0.047 \\
\hline \multicolumn{6}{|l|}{ Cells with haustoria } \\
\hline 2 days & 0.29 & 2.02 & 5.34 & 798 & 0.0001 \\
\hline 4 days & 0.84 & 9.85 & 40.07 & 598 & 0.0001 \\
\hline 6 days & 0.98 & 11.27 & 50.85 & 598 & 0.0001 \\
\hline \multicolumn{6}{|l|}{ Cells collapsed } \\
\hline 2 days & 1.07 & 0 & $\ldots$ & $\ldots$ & $\ldots$ \\
\hline 4 days & 3.39 & 0 & $\ldots$ & . & $\ldots$ \\
\hline 6 days & 5.51 & 0 & $\ldots$ & $\ldots$ & $\ldots$ \\
\hline
\end{tabular}

${ }^{a}$ Compatible (comp.) and incompatible (incomp.) interactions were achieved by inoculation with races $\mathrm{E} 2$ and $\mathrm{E} 1$, respectively.

b Values for stomata per section and stomata penetrated are means of 50 sections examined. Values for cells with haustoria and collapsed cells are means of 200 to 400 microscope fields, each containing 144 cells.

c Because of the high degree of freedom (df) values, differences between means are considered significant only at $P<0.01$. 
appearance of the first haustorium are related to nonhost resistance (7).

The first observation of the formation of a haustorium was made $17 \mathrm{~h}$ after inoculation. The early stages of haustorial differentiation appeared to be similar in compatible and incompatible interactions. The differentiation of the first haustoria within the first day after inoculation has also been observed in the M. larici-populina$P$. nigra interaction $(21,25)$, in the $M$. medusae- $P$. deltoides interactions $(22,25)$, and in the $M$. lini-Linum interactions $(4,11)$.

Compatible interaction. In the compatible interaction between M. larici-populina and poplar, haustorial formation was very similar to that observed in a number of other pathosystems involving dikaryotic haustoria (e.g., 11,12). The host cells containing haustoria appeared similar to the healthy adjacent cells, suggesting that the host cells were not harmed by the intracellular penetration of the compatible race. Furthermore, the viability of the haustorial body appeared to be generally maintained until initiation and development of uredinia several days later. In fact, we did not observe the collapse of any haustoria-containing host cells throughout the course of the study. This result differs from observations of compatible interactions between $M$. medusae and P. deltoides (22). Such a discrepancy may result from the fact that the rust isolate utilized by Shain and Järlsfors (22) may not have been pure, whereas we used controlled inoculations. Uredinial ontogeny in $M$. larici-populina has previously been described $(23,24)$, and our observations appear to confirm these earlier reports.

Incompatible interaction. It is generally accepted that in infections involving obligate biotrophic parasites such as rust fungi, hostspecific resistance is expressed after the appearance of the first fungal haustorium (7). In the M. larici-populina $-P$. deltoides $\times P$. nigra interaction, we clearly observed such an expression of host-specific resistance. Our first observations of the expression of incompatibility toward race E1 were recorded $19 \mathrm{~h}$ after inoculation. This incompatibility is characterized by the collapse and disorganization of the infected host cells. The host response that accompanied intracellular penetration by the incompatible race E1 was extremely localized, and 2 days after inoculation, only $0.73 \%$ of the mesophyll cells had collapsed. The host response was so spatially limited that no symptoms of rust attack could be detected at the macroscopic level on the surfaces of infected leaves. Thus, the incompatibility of cultivar Ogy toward race E1 of M. larici-populina appears to be mediated by a hypersensitive response, since the observed symptoms closely match the definition given by Goodman and Novacky (6).

In this study, we describe in detail the developmental time course for both a compatible and an incompatible race of $M$. laricipopulina toward one hybrid poplar cultivar under controlled conditions. Now we will be able to use this model system to investigate the defense response of poplar toward M. larici-populina at the molecular level. In particular, with the recent identification of the locus conferring resistance to M. larici-populina (Mer locus) $(2,10)$, this model could be used to perform in situ hybridization studies on the expression of resistance genes located at the $\mathrm{Mer}$ locus once such genes have been cloned.

\section{ACKNOWLEDGMENTS}

We thank J. Pinon (INRA-Nancy, France) for providing us with rust races, and S. Hawkins (Antenne Scientifique Universitaire de Chartres, France) for critical review and linguistic corrections of the manuscript.

\section{LITERATURE CITED}

1. Bruzzese, E., and Hasan, S. 1983. A whole leaf clearing and staining technique for host specificity studies of rust fungi. Plant Pathol.
42:337-343.

2. Cervera, M. T., Gusmao, J., Steenackers, M., Peleman, J., Storme, V., Vanden Broeck, A., Van Montagu, M., and Boerjan, W. 1996. Identification of AFLP molecular markers for resistance against Melampsora larici-populina in Populus. Theor. Appl. Genet. 93:733-737.

3. Chandrashekar, M., and Heather, W. A. 1981. Temperature sensitivity of reactions of Populus spp. to races of Melampsora larici-populina. Phytopathology 71:421-424.

4. Coffey, M. D., Palevitz, B. A., and Allen, P. J. 1972. The fine structure of two rust fungi, Puccinia helianthi and Melampsora lini. Can. J. Bot. 50:231-240.

5. Giorcelli, A., Vietto, L., Anselmi, N., and Gennaro, M. 1996. Influence of clonal susceptibility, leaf age and inoculum density on infections by Melampsora larici-populina races E1 and E3. Eur. J. For. Pathol. 26: 323-331.

6. Goodman, R. N., and Novacky, A. J. 1994. The Hypersensitive Reaction in Plants to Pathogens: A Resistance Phenomenon. American Phytopathological Society, St. Paul, MN.

7. Heath, M. C. 1981. A generalized concept of host-parasite specificity. Phytopathology 71:1121-1123.

8. Heath, M. C. 1997. Signalling between pathogenic rust fungi and resistant or susceptible host plants. Ann. Bot. 80:713-720.

9. Larson, P. R., and Isebrands, J. G. 1971. The plastochron index as applied to developmental studies of cottonwood. Can. J. For. Res. 1:1-11.

10. Lefévre, F., Goué-Mourier, M. C., Faivre-Rampant, P., and Villar, M. 1998. A single gene cluster controls incompatibility and partial resistance to various Melampsora larici-populina races in hybrid poplars. Phytopathology 88:156-163.

11. Littlefield, L., and Bracker, C. E. 1972. Ultrastructural specialisation of the host-pathogen interface in rust-infected flax. Protoplasma 74:271305 .

12. Littlefield, L., and Heath, M. C. 1979. Ultrastructure of Rust Fungi. Academic Press, London.

13. Manocha, M. S., and Shaw, M. 1967. Electron microscopy of urediospores of Melampsora lini and rust-infected flax. Can. J. Bot. 45:15751582.

14. Mendgen, K., and Deising, H. 1993. Tansley review no. 48: Infection structures of fungal plant pathogens-A cytological and physiological evaluation. New Phytol. 124:193-213.

15. Newcombe, G., Bradshaw, H. D., Jr., Chastagner, G. A., and Stettler, R. F. 1996. A major gene for resistance to Melampsora medusae f. sp. deltoidae in a hybrid poplar pedigree. Phytopathology 86:87-94.

16. Pichot, C., and Tessier du Cros, E. 1993. Susceptibility of P. deltoides Bartr. to Melampsora larici-populina and M. allii-populina. I. Qualitative analysis of a $6 \times 6$ factorial mating design. Silvae Genet. 42:179-188.

17. Pinon, J., and Tessier du Cros, E. 1976. Sensibilité aux rouilles de différentes espèces de peupliers à Melampsora larici-populina Kleb. et $M$. allii-populina Kleb. Ann. Sci. For. 33:49-59.

18. Pinon, J., and Valadon, A. 1997. Behaviour towards major parasites of poplar cultivars registered in European Union. Ann. Sci. For. 54:19-38.

19. Pinon, J., Van Dam, B. C., Genetet, I., and De Kam, M. 1987. Two pathogenic races of Melampsora larici-populina in north-western Europe. Eur. J. For. Pathol. 17:47-53

20. Prakash, C. S., and Thielges, B. A. 1989. Interaction of geographic isolates of Melampsora medusae and Populus: Effect of temperature. Can. J. Bot. 67:486-490.

21. Rijkenberg, F. H. J. 1972. Fine structure of the poplar rust (Melampsora larici-populina). Phytophylactica 4:33-40.

22. Shain, L., and Järlfors, U. 1987. Ultrastructure of eastern cottonwood clones susceptible or resistant to leaf rust. Can. J. Bot. 65:1586-1598.

23. Sharma, J. K., and Heather, W. A. 1978. Occurrence of abnormal forms of urediniospores in Melampsora larici-populina. Trans. Br. Mycol. Soc. 71:154-162.

24. Spiers, A. G., and Hopcroft, D. H. 1985. Ultrastructural studies of pathogenesis and uredinial development of Melampsora larici-populina and M. medusae on poplar and M. coleosporioides and M. epitea on willow. N.Z. J. Bot. 23:117-133.

25. Spiers, A. G., and Hopcroft, D. H. 1990. Ultrastructural studies of interactions between resistant and susceptible poplar cultivars and the rusts, Melampsora medusae and Melampsora larici-populina. N.Z. J. Bot. 28: 307-322

26. Villar, M., Lefévre, F., Bradshaw, H. D., and Tessier du Cros, E. 1996. Molecular genetics of rust resistance in poplars (Melampsora laricipopulina Kleb./Populus sp.) by bulked segregant analysis in a $2 \times 2$ factorial mating design. Genetics 143:531-536. 